\title{
LA PRIMERA BIENAL INTERAMERICANA DE PINTURA Y GRABADO
}

\author{
$\mathbf{P} \mathbf{O}$
}

\section{A VIE R M O Y S E N}

I presentación de la Primera Bienal Interamericana de Pintura y L Grabado, verificada en el Palacio de las Bellas Artes de la Ciudad de México, * fue, a no dudarlo, uno de los acontecimientos artísticos más importantes que se han celebrado aquí en los últimos años. Por primera vez con una trascendencia continental, se mostró a los ojos de la crítica, las diversas modalidades artísticas que desarrollan los pintores y grabadores de los veintiún paises americanos.

La importancia de esta Primera Bienal pronto quedó de manifiesto, pues antes de su inauguración despertó las más encendidas controversias entre espíritus al parecer increíblemente misoneístas y aquellos más abiertos a la comprensión universal del hombre. En este enorme muestreo de la pintura y grabado de todo un continente, de manera elocuente mostráronse las tres corrientes vigorosas que le personifican en materia de arte. Por un lado el expresionismo abstracto de los norteamericanos por la otra, la singularisima pintura mexicana, y finalmente la del genial brasileño Cándido Portinari. Sobre estas tres modalidades puede decirse que gira la pintura americana, puesto que quién más, quién menos, se encarga de imitarles, de seguirles. Empero fue de advertirse el gusto cada vez más dominante hacia un arte no figurativo, fuera de toda realidad inmediata.

* Organizada por el I. N. B. A., del 6 de junio al 30 de septiembre. Para mayores datos véase el Catálogo de las exposiciones de arte en 1958, preparado por el doctor Justino Fernández, ahí se da nota detallada de los artistas y obras presentadas. 
No todos los países participantes tuvieron la misma calidad e importancia, máxime cuando se descubrieron las ausencias notorias de reconocidos maestros. De los conjuntos nacionales que merecen destacarse, habrá que anotar, desde luego, a los Estados Unidos. En efecto, el lote norteamericano fue de los que levantaron de inmediato múltiples y disímbolas opiniones; con todo, fue magnífico, tanto por su unidad como por la oportunidad que ofreció para conocer y estudiar los valores de una manifestación estética que puede, o no, convencer, pero cuya presencia no se puede negar dentro de la cultura de este medio siglo. El expresionismo abstracto de Norteamérica se hizo presente con las interesantes obras de Mark Tobey, Franz Kline, Gabor Peterdi y Sam Francis que preside la célebre Escuela del Pacífico. Buen conjunto fue el de Puerto Rico, sin embargo, habría ganado muchísimo más si se hubiese apretado la selección de artistas, enviando de los escogidos, un mayor número de cuadros. La presencia de Roberto Matta fue sin duda lo mejor de Chile, aun cuando habría que anotar los nombres de Carmen Silva y Jorge Díaz. De los colombianos destacó, por sus finas calidades, Guillermo Silva Santamaria, mas no hay que olvidar la presencia de Judith Márquez, Jaime López Correa y Lucy Tejeda. Curioso conjunto fue el canadiense pues mostró las dos corrientes que le forman: la influencia norteamericana con su abstraccionismo, y lo francés de hace treinta años, a la manera de los intimistas estilo Pierre Bonnard; los delicados y poéticos cuadritos de Alexander Coville, fueron de lo mejor. Pintura fresca, de vivo colorido y de un primitivismo candorosamente intencionado fue la que presentó, con novedad, Haití. Un lote casi uniforme constituyó el de Argentina, pues mostró hasta que punto se han impuesto los gustos y teorias estéticas abstraccionistas del crítico Jorge Romero Brest. Aproximadamente la mitad de la sección argentina representó esta modalidad; el premio otorgado a la pintora Forner fue acertado, pues su obra está precisamente "entre fronteras", es decir, entre lo figurativo inmediato y lo abstracto mediato. Frente al expresionismo abstracto de los norteamericanos, destacó vigorosamente la pintura mexicana. Dos extremos y dos personalidades claramente definidas de las cuales preferimos la de México, pues la otra, que duda cabe, no dice nada o dice poco, y los mismos valores se encuentran en una obra procedente de Amsterdan que en otra de Túnez, Brasil o Tokio; en este renglón la Bienal fue más que elocuente. A nuestro juicio el lote mexicano estuvo mediocremente seleccionado por los propios artistas concursantes. Sin embargo, lo salvaron, aparte de Goitia, Cordelia 
Urueta, Juan Soriano, Jesús Guerrero Galván, y sobre todo, los dos cuadros de ese gran maestro que es ya, Guillermo Meza.

Cuatro exposiciones retrospectivas en homenaje a José Clemente Orozco, Diego Rivera, David Alfaro Siqueiros y Cándido Portinari fueron presentadas dentro de la Bienal, lo cual fue un gran acierto por cuanto nos permitieron valorizar, en conjunto, la extraordinaria obra de estos maestros americanos. Mas aquí también se impuso una pequeña selección. De los mexicanos sobresalió; como siempre, el arte vital de Orozco, con sus impresionantes series de "Los Teules", y esas críticas tremendas sobre los nefandos y apocalípticos militarismos. La selección de obras de Rivera dejó mucho que desear, no hubo unidad ni sentido en la disposición de sus cuadros. El caso de Siqueiros es curioso, pues son superiores alguno pequeños cuadros suyos como "Las Campesinas" y el "Guerrillero", todos ellos poesia, color y gran arte, y no asi ese gran mural que pintó para la Bienal con un "realismo" inaceptable a estas alturas. Espectáculo de arte supremo fue la presencia de Cándido Portinari con su vigorosa y excelente pintura, preñada de rítmicas formas, de profundas $y$ humanas intenciones, y de bellas calidades de color.

La sección de grabado rivalizó, por su parte, con la pintura pues mostró inmediatamente una novedad, coherencia y calidad que en aquélla no fue posible encontrar. QQué manejo de las formas y de las técnicas! y qué maestría fue la mostrada en general por todos los concursantes. Destaquemos tan sólo algunos nombres y países. Desde luego Cuba, representada con una serie de admirables xilografías, la tradición más pura en el arte del grabado; las mejores debidas a Carmelo González, Armando Posse y Lesbia Van Dumois. De Puerto Rico, Rafael Tufiño, Carlos Raquel Rivera y Augusto Marín; y de los chilenos, acaso el mejor, Roser Bru. De los Estados Unidos, aparte del maestro Lasansky, sobresalian Leonard Baskin y Gabor Peterdi. El grabado brasileño acorde con la calidad de la pintura de Portinari, pues hay mayor unidad y originalidad ahí que no con la pintura de los otros artistas. Magníficas obras fueron las que enviaron los grabadores canadienses. Pompeyo Audivert estuvo a la cabeza del lote argentino. En cuanto al grabado mexicano es indudable que mantiene su calidad y destaca su acentuado carácter social, pero ante tantas posibilidades y recursos técnicos ahí mostrados, se nos antojó un tanto monótono en la técnica general y cansado, sobre todo, en la usual temática.

Cinco grandes premios fueron destinados a la pintura y tres a las obras de grabado: El jurado encargado de otorgarlos: estuvo constituído 
por las siguientes personas, para pintura: el critico guatemalteco Luis Cardoza y Aragón, la pintora cubana Amelia Peláez; los pintores Antonio Rodríguez Luna, de España y Helmut Hungerland de los Estados Unidos; más los criticos mexicanos Doctor Justino Fernández, Jorge Juan Crespo de la Serna y el pintor David Alfaro Siqueiros. Para el grabado: Luis Cardoza y Aragón, Antonio Rodríguez Luna, Helmut Hungerland, Justino Fernández, J. J. Crespo de la Serna, Alfaro Siqueiros y los grabadores mexicanos Leopoldo Méndez y Gabriel Fernández Ledezma.

Francisco Goitia ganó el Gran Premio Internacional, otorgado por la Secretaría de Educación Pública de México. El segundo premio, del Instituto Nacional de Bellas Artes, correspondió al americano Jack Levine. Raquel Forner, pintora argentina, alcanzó el tercer premio, el de la Prensa de México, cedido por el diario "Novedades". El cuarto premio, de la Nación (sólo para mexicanos) fue dado al célebre doctor Atl. José Echave, del Uruguay, conquistó el quinto premio, de las Naciones (exclusivo para un pintor de América, no mexicano). Los tres premios para el grabado los ganaron: Alberto Beltrán, mexicano, Premio Panamericano, de la U. N. A. M. El segundo, Mauricio Lasansky, norteamericano, Premio José Guadalupe Posada. $\mathrm{Y}$ al portorriqueño Carlos Raquel Rivera le fue concedido el premio del Departamento de Bellas Artes.

La Primera Bienal Interamericana de Pintura y Grabado, significó una vital experiencia para un pais que como México ha dado al mundo del arte una gran contribución con su pintura mural contemporánea. Vista a distancia es posible hacer un breve balance con un saldo positivo a su favor, pese a los vicios y errores que desde un principio mostró y de los cuales destacamos, a criterio nuestro, la inconcebible exclusión que se hizo de los pintores extranjeros nacionalizados o radicados aquí; extraña fue, también, la exclusión de los nuevos valores de la pintura mexicana. Como éstas, otras ausencias no dejaron de significarse pues tal vez con su presencia algunos conjuntos nacionales habrían ganado. Pero nuestra crítica mayor está en contra de la admisión de Atl y Goitia como artistas concursantes; su participación, honrosa por otra parte, debió ser puramente de homenaje pues restó posibilidades, por razones fácilmente comprensibles, para que triunfaran los otros artistas. La presencia de Francisco Goitia con su ya clásico "Tata Jesucristo", no dejamos de comprender que dignificó a la Bienal, mas nos parece injusto el premio que se le dio, no porque no lo merezca un gran maestro como él, pero todos sabemos que su obra extraordinaria obedece, más bien, a un tiempo y un espacio determinados por circunstancias históricas. Ia obra poética del Hombre 
se hace $y$ rehace constantemente, $y$ un estímulo mayor habría resultado tal premio para un Guillermo Meza o un Juan Soriano que con su pintura están rehaciendo hoy, la obra del Hombre.

Repetimos, sin embargo, que la Primera Bienal tiene un saldo a su favor. Vimos, por ella, la expresión pictórica de un gran continente que pugna por presentarse con bella originalidad. Las exposiciones de homenaje, con Portinari y Orozco a la cabeza, le justifican ampliamente. Además, parece que la Bienal fue un antecedente necesario para la creación del Museo Nacional de Arte Moderno que se inauguró días después de clausurada. Por otra parte, algo de provecho habrá que esperar de las controversias ideológicas que motivó "conmoviendo a nuestro mundo cultural", y esto último, ¿no es ya un resultado positivo?, según advirtiera Cardoza y Aragón. Creemos, finalmente, que fue positiva si pensamos que en México, por razones muy justificadas, todos hablamos del mérito que guarda nuestra pintura, pero a la vez y esto con un criterio pueril, se suele condenar todo aquello que por un desconocimiento directo no se comprende en materia de arte; ya se entiende que en este aspecto la Bienal fue toda una experiencia reveladora, pues con ella o se fundamenta, reafirmándose, nuestro gusto estético, o bien, le abrimos nuevas posibilidades expresivas adecuadas a la nobleza de sus principios universales, toda vez que hemos visto frente a otras manifestaciones estéticas, esta pintura nuestra. La experiencia de la Bienal, habrá de dejarnos una conciencia real sobre el valor positivo de lo que somos y de lo que hemos hecho, artísticamente, en este medio siglo. 